\title{
INTERPERSONAL METAPHOR OF MOOD IN ANTHONY DOERR'S NOVEL ALL THE LIGHT WE CANNOT SEE
}

\author{
Ali Sofyan, Sri Wulan \\ Faculty of Literature \\ Universitas Islam Sumatera Utara (UISU), Medan, Indonesia \\ E-mail: alisofnas@gmail.com
}

Received: 2021-04-23

Accepted: 2021-05-24

\begin{abstract}
This study aims to explore the transference of mood in interpersonal metaphor. The design method is descriptive and the approach is qualitative research. The main data are taken from the novel All the Light We Cannot See written by Anthony Doerr. The analysis is done by identifying the interpersonal metaphor of mood in the novel, describing them, and determining the dominant transference by using the percentage formula. 160 pages or one-third of the novel were taken as the data of this study. By completing the steps of the objectives, the significance is to give a thorough comprehension about interpersonal metaphor of mood and the transferences occurred in the sentences whether it is in texts or in speeches. The finding shows that the dominant mood found in the novel is declarative which reaches $44 \%$ occurrences. The second mood, which often occurs in the novel, is interrogative with $40 \%$. The third is command in interrogative mood with $12 \%$ occurences and the statement in imperative mood follows with $4 \%$ occurrences; while there two patterns which cannot be found in the novel. They are question in declarative mood and imperative mood. It implies that most sentences in the novel give command in declarative form.
\end{abstract}

Keywords: metaphor, interpersonal, transference of mood

\section{Introduction}

People often find some difficulties when conveying their ideas to readers or listeners on both written and spoken language. It is safe to say that they are in desperate need of finding ways to transfer their imaginations through text or verbiage; here we find the use of metaphors. The first reason to use metaphors is to give people a picture in their minds of what is being discussed. For example, if one is trying to get a listener or reader to see how beautiful the subject's personality is, he or she might use the metaphor, "she is an angel". Angel is an entity whose characteristics are known to be beautiful, and perfect in some ways. Thus, the comparison of the subject's personality to an angel means that "she is so beautiful".

Another reason to use metaphors is to help people understand a concept. Extended metaphors are especially useful for this. An extended metaphor is a metaphor that lasts for multiple lines and has symbols that keep the metaphor going. Metaphors 
can also be used to simply make the writing more interesting. If a writer uses literal language, especially in fiction or literary non-fiction, the writing can be boring and dry. Coming up with original metaphors helps to make the writing more interesting while, as stated above, helping listeners or readers to understand what people are trying to convey.

The way we talk about complex and abstract ideas is suffused with metaphor. Metaphor is everywhere in literature, from the interrelations among its smallest (words, images, figures of speech) to its largest (characters, plot, narrative) elements. Beyond the most basic assumptions about metaphor - that it has a primarily decorative purpose, to make writing more "exciting" or "beautiful;" or that it helps the reader "visualize" images; or that it serves to highlight and heighten important themes - lie great areas of thinking about metaphor, that can help deepen and clarify our understanding of literature, art and life. Transferences of metaphor occur a lot in daily conversations and published writings such as novels. This is meant to get variations of wordings and most of times to amplify or soften the intention by changing the mood.

As for the source material of this study, Anthony Doerr's novel All the Light We Cannot See is chosen, and this novel tells about a blind French girl and a German boy whose paths collide in occupied France as both try to survive the devastation of World War II. The novel was published by Scribner in 2004 and it won the 2015 Pulitzer Prize for Fiction and the 2015 Andrew Carnegie Medal for Excellence in Fiction.

This research is conducted to identify and analyze the transferences in interpersonal metaphor of mood. The other types of metaphor are outside the scope. The novel that was used as the object of this study is All the Light We Cannot See, published by Scribner in the United Kingdom in 2014, consisting of 531 pages sectioned into thirteen chapters. The writer of this study analyzes more than one-third of the novel.

Hopefully, this study can increase readers' knowledge in identifying the mood transferences in texts and conversations, and writers' skill making good sentences in English, especially interpersonal metaphor.

\section{Literature Review}

Metaphor is viewed as meaning representation from two sides; one is literally and the other is metaphorically (Searle 1993: 83). Metaphor is divided into lexical metaphor, which is the traditional understanding of metaphor (Lakoff and Johnson, 2003) and grammatical metaphor, which is pioneered by Halliday. Lakoff's metaphor is much more to the literature; meanwhile,Halliday's is much more to the text and context. Halliday (1994: 340) defines metaphor as a word used for something resembling that which it usually refers to. Grammatical metaphor is divided into ideational metaphor (sometimes called as experiential metaphor) and interpersonal. In Halliday's definition, when something is metaphorically written or spoken, it is done not in congruent or natural fashion.

\subsection{Grammatical Metaphor}

Grammatical metaphor is the transference in the expression of meanings from a congruent representation to another incongruent realization that involves changes in the level of clauses, groups/phrases, words and morphemes. Grammatical metaphor is divided into two types: 


\subsubsection{Ideational Metaphor}

This type of metaphor does incongruent coding involving transferences from the congruent form of types of the clauses and types of the processes and the participants used. For instance, the congruent expression such as "He departed to the station immediately so that he was safe from the fatal accident" may be transferred into its corresponding grammatical metaphoric expression "His immediate departure to the station saved him from the fatal accident".

Such incongruent coding which is characterized by high degree of lexical density and low degree of grammatical intricacy is generally used in the written language. On the other hand, congruent coding which is characterized by low degree of lexical density and high degree of grammatical intricacy is used in the spoken language. An expression is said to be congruent if it is coded by using the normal grammatical categories in terms of experiential functions as given below: a thing coded by a noun, an event or activity coded by a process, quality coded by an adjective, location, time, manner coded by a circumstance, relation coded by a conjunction, position coded by a preposition, and judgment, opinion or comment coded by modality.

Note that grammatical metaphor in terms of experiential metaphor is naturally used in the written language in the description of science and technology, which is associated to objectivity, impersonality, technicality, and practicality. Thus, such features characterize the lexico-grammatical realizations of experiential metaphor as (a) dominant use of relational process, (b) in the passive voice, and (c) with low degree of grammatical intricacy and high degree of lexical density. Grammatical intricacy is associated with the number of clauses in a clause complex and lexical density is based on the less number of lexical categories in the clause (Suhadi, 2015).

\subsubsection{Interpersonal Metaphor}

Halliday (1985) notes that interpersonal metaphor is categorized into metaphors of mood and modality, creating a stratal tension between discourse semantics and lexicogrammar. Mood metaphors construe a discourse semantic speech function through an incongruent mood option in grammar. To illustrate, the speech function command might be realized as a command, e.g. Get up! using imperative mood. Alternatively, command might also be realized as a suggestion as in Why don't you get up? using interrogative mood. Mood metaphors are found more commonly in spoken language. However, the second type of interpersonal metaphor, metaphors of modality, is more likely to be found in written language.

Halliday in Suhadi (2015) states that interpersonal metaphor is the incongruent coding involving types of clause involving mood and modality. Normally, the congruent coding of a statement is realized with a declarative, a question with an interrogative, and a command with an imperative. Note that an offer does not have an unmarked congruent realization in mood. Here are some examples of transference of mood from congruent coding into incongruent coding in terms of interpersonal metaphor of mood:

a. A statement expressed in the interrogative mood.

- That is not the character of a university student.

- Is that the character of a university student?

b. A statement expressed in the imperative mood.

- Ali: Where is my new bag, Mom?

- Mom: I put somewhere in the cupboard.

- Look for it in the cupboard! 
c. A command expressed in the interrogative mood.

- Switch on the air-conditioner!

- Could you switch on the air-conditioner?

d. A command expressed in the declarative mood.

- Don't challenge your father!

- You should not challenge your father.

e. A question expressed in the declarative mood.

- Do you know her name?

- I ask you whether you know her name.

f. A question expressed in the imperative mood.

- Who hasn't got the hand-out?

- Raise your hand if you haven't got the hand-out.

In many instances a question may be answered in three different moods: declarative, imperative or interrogative.
A : Where is my notebook?
B : : It is in the cupboard. (Declarative)
Find it in the cupboard. (Imperative)
Have you looked for it in the cupboard? (Interrogative).

\subsection{Lexical Metaphor}

Lexical Metaphor is an indirect comparison of a lexical item with another item which has some features in common. With two lexical items directly compared with the words as or like it is called simile, not metaphor such as in Her heart is like a stone or Her heart is as hard as a stone (Suhadi, 2015).

\section{Research Method}

This study uses descriptive design with qualitative approach. Matin (2004:70) notes that descriptive research design is to portray accurately the characteristics of a particular situation or group or individual with or without special initial hypotheses about the nature of these characteristics. Descriptive research is a research method that describes and interprets object appropriate with situation (Best, 1982:119). The process of classifying or labelling various kinds of data and preparing a data index is the essential step in the organization of qualitative research.

In this study, data are collected from 160 pages or one-third of the novel. The data are arranged in several steps such as administering, verifying, and classifying the chosen data, which were conducted as follows:

1. Identifying the interpersonalmetaphor of mood based on the theory proposed by Halliday (1985).

2. Determining the dominant transference of moodin interpersonal metaphor found.

3. Describing each transference of mood in interpersonal metaphor by using the percentage formula (Ary et al, 1979:108) as follows:

$$
F=\frac{X}{Y} \times 100 \%
$$

Note:

- $\mathrm{F}=$ The percentage of the obtained transference of mood in interpersonal metaphors.

- $X=$ Frequency of each transference of mood in interpersonal metaphors occurrences. 
- $\mathrm{Y}=$ The sum of interpersonal metaphors of mood.

\section{Discussion}

Transferences of interpersonal metaphor of mood found in the novel:

a. Statement realized with interrogative

1. "Why doesn't he say where he is, Werner?"

"Maybe because he doesn't want us to know?" (p. 53)

The underlined sentence answers the question before with an interrogative mood instead of declarative mood because the speaker is not sure about the answer.

2. Didn't she presume she would live with her father in Paris for the rest of her life? That she should always sit with Dr.Geffard in the afternoons? That every year, on her birthday, her father would present her with another puzzle and another novel, and she would read all of Jules Verne and all of Dumas and maybe even Balzac and Proust? That her father would always hum as he fashioned little buildings in the evenings, and she would always know how many paces from the front door to the bakery (forty) and how many more to the brasserie (thirty-two), and there would always be sugar to spoon into her coffee when she woke? (p. 72)

The paragraph is about the speaker questioning her fate, wishing what would have happened if the war had not broken.

3. "What are you listening to?"

She crosses her arms and puts the earphone back and does not answer.

"Are you listening to something you're not supposed to be listening to?"

"What do you care?" (p. 73)

The underlined sentence is about the second speaker answering the question with an interrogative mood, declaring that she might be listening to something she is not supposed to be listening to.

4. "People say it must not be a great posting, here at the mines," says Herr Siedler. "They say: 'Wouldn't you rather be in Berlin? Or France? Wouldn't you rather be a captain at the front, watching the lines advance, away from all this"'---he waves his hand at the window---“"soot?'But I tell them I live at the center of it all. I tell them this is where the fuel is coming from, the steel too. This is the furnace of the country." (p. 84)

The underlined questions is a statement that Herr Siedler should have a better fortune if he is posted in Berlin or France, be the captain at the front, instead of staying there in the mines.

5. "Is it right," Jutta says, "to do something only because everyone else is doing it?" (p. 133)

This rhetorical question states that it is not right to do something only because everyone else is doing it.

6. "What else can you make?"

Werner studies the parts on his table. "A doorbell, sir? Or a

Morse beacon? An ohmmeter?" (p. 149) 
The underlined answers stated in interrogative mood are to show that the speaker has the ability to make them all.

7. "The Lycée Charlemagne, is that right? On the rue Charlemagne?"

The skin around the assistant director's eyes stretches.

"Where you daughter goes to school?" Von Rumpel turns in his chair. "And the College Stanislas, isn't it, Dr.Hublin? Where your twin sons attend? On the rue Notre-Dame des Champs? Wouldn't those handsome boys be preparing to walk home right now?"

Hublin sets his hands on the back of the empty chair beside him, and his knuckles become very white.

"One with a violin and the other a viola, am I correct? Crossing all those busy streets. That is a long walk for ten-year-old boys."

(p. 177)

All the questions above are threats from Von Rumpel towards Dr.Hublin, saying that he knows his identity and the whereabouts of his family.

8. "Is it hidden, Uncle? Could someone see it if the house were searched?"

"Who would search the house?" (p. 182)

The underlined answer in interrogative mood indicates that the Uncle believes that house will not be a target for searching.

9. Frau Elena's midnight passage among the beds like an angel, murmuring, I know it's cold. But I'm right beside you, see? (p. 193-194)

The underlined sentence ended with a question mark can be interpreted that it is safe since Frau Elena is with them.

10. When he demands to use a telephone, the guards don't bother to laugh. "Do you know the last time we used a telephone?" (p. 197)

The question above is an irony, stating that the guards never use a telephone for a long time.

\section{b. Statement realized with imperative}

1. "How many radios do you have, Uncle?"

"Let me show you." He brings her hands to a shelf. "This one is stereo. Heterodyne. I assembled it myself." (p. 134)

\section{c. Command realized with interrogative}

1. Etienne adopts a British accent. "Good evening, mademoiselle, why don't you come to the jungle with me and eat these butterflies, they are as big as dinner plates and may not be poisonous, who knows?" (p. 151)

2. "Could you read some more, please?" she asks, and Etienne opens the book and whispers, "Delight itself is a weak term to express the feelings of a naturalist who, for the first time, has wandered by himself into a Brazilian forest ..." (p. 157)

3. "Is there somewhere," he says, "we can talk?" (p. 174) 
The interpretation of the question above is "Let's talk somewhere."

\section{d. Command realized with declarative}

1. He picks her up and spins her around three times. "Now," he says, "you're going to take us home." (p. 36)

2. "I want you to think of the model, Marie." (p. 36)

3. The children sing and devour the pudding, Frau Elena says, "Time's up," and Werner switches off his receiver. (p. 68)

4. Objects patter onto the roof---shell fragments? cinders?---and Marie-Laure says aloud, "You are too high in the house," and forces herself out from beneath the bed... (p. 100)

5. "You will work in the laboratory after dinner. Every night. Even Sundays."

"Yes, sir." (p. 154)

6. After a few paragraphs, Marie-Laure says without preamble, "Tell me about that bedroom upstairs. Across from the one I sleep in." (p. 158)

7. "When I raise my left hand, you run. When I raise my right hand, the rest of you fools run." Off Bastian waddles, rubber hose around his neck, pistol swinging at his side. (p. 169)

8. He sets down his cup of tea and says, "I would like to see your most protected specimens. I am most specifically interested in a specimen I believe you have only recently brought out from your vaults." (p. 175)

9. "I would like to see the minerals you do not reveal to the public. One in particular." (p. 176)

10. Von Rumpel does not raise his voice. "You will wait here. Both of you. You will wait here with me until I see what I have come to see. And then we will all go back to our important jobs." (p. 176)

11. Von Rumpel says, "I know it is not here, messieurs. Not even the lowest janitor would be so stupid as to leave the diamond here. But I would like to see where you have kept it. I would like to know what sort of place you believe is safe enough." (p. 177-178)

\section{e. Question realized with declarative}

The author does not find any sentence that has the pattern of this transference.

\section{f. Question realized with imperative}

The author does not find any sentence that has the pattern of this transference.

The finding shows that the number of each transferences of mood in interpersonal metaphor is found in the novel. Then, the data are converted into a percentage table below. Based on the data analysis, the result can be presented as follows:

\begin{tabular}{|l|c|c|}
\hline $\begin{array}{c}\text { Transference of Mood in } \\
\text { Interpersonal Metaphor }\end{array}$ & Number & Percentage \\
\hline Statement $\rightarrow$ Interrogative & 10 & $40 \%$ \\
\hline Statement $\rightarrow$ Imperative & 1 & $4 \%$ \\
\hline
\end{tabular}




\begin{tabular}{|l|c|c|}
\hline Command $\rightarrow$ Interrogative & 3 & $12 \%$ \\
\hline Command $\rightarrow$ Declarative & 11 & $44 \%$ \\
\hline Question $\rightarrow$ Declarative & 0 & $0 \%$ \\
\hline Question $\rightarrow$ Imperative & 0 & $0 \%$ \\
\hline Total & $\mathbf{2 5}$ & $\mathbf{1 0 0}$ \\
\hline
\end{tabular}

Table 1. Percentage and the Number of Lexical Metaphor

The above table shows that the dominant mood found in the novel is declarative which reaches $44 \%$ occurrences. The second mood which often occurs in the novel is interrogative with $40 \%$. The third is command in interrogative mood with $12 \%$ occurences and the statement in imperative mood follows with $4 \%$ occurrences. While, there two patterns which cannot be found in the novel. They are questions in declarative mood and imperative mood. This implies that most sentences in the novel give command in declarative form.

\section{Conclusion}

The conclusion is that no sentence which matches the pattern of the question realized in declarative mood $(0 \%)$ and the question realized in imperative mood $(0 \%)$, while the most dominant transference is the command realized in declarative mood with 11 occurrences $(44 \%)$, followed by the statement realized in interrogative mood with 10 occurrences $(40 \%)$. Then comes the command realized in interrogative mood with 3 occurrences $(12 \%)$, followed by the statement realized in imperative mood with 1 occurrence $(4 \%)$.

\section{References}

Best, J.W. (1982). Research in Education. New Jersey: Prentice Hall Inc.

Doerr, A. (2014). All the Light We Cannot See. New York: Scribner

Halliday, M.A.K. (1985). An Introduction to English Functional Grammar. London: E. Arnold Publishers Ltd.

Lakoff, G., and Johnson, M. (2003) Metaphors we live by. London: The university of Chicago Press.

Matin, A. (2004). Research Method, Statistic, IT, and e-Methods. New Delhi: Icon Publications PVT Ltd.

Searle, J. R. (1993). Metaphor in A. Ortony (Ed.). Metaphor and thought (pp. 83-111). Cambridge: Cambridge University Press. https://doi.org/10.1017/CBO9781139173865.008

Suhadi, J. (2015). Course in English Functional Grammar. Medan: LPPM UISU Press.

Suhadi, J. (2015). Interpersonal Metaphor of Mood Applied to some verses of the Holy Al-Qurán. Miqot, 36(2). https://media.neliti.com/media/publications/153132EN-interpersonal-metaphor-of-mood-applied-t.pdf. 